\title{
Comparison of Periodontal Status in Patients with Chronic Obstructive Pulmonary Disease and Healthy Subjects
}

\author{
Mohammad Ayoub Rigi-Ladiz, ${ }^{1}$ Nezar Ali Moulaei, ${ }^{2}$ Nahid Ramazani, ${ }^{3, *}$ and Mohaddese \\ Khajemahmood ${ }^{4}$ \\ ${ }^{1}$ Associate Professor, Oral and Dental Disease Research Center, Dept of Periodontics, School of Dentistry, Zahedan University of Medical Sciences, Zahedan, IR Iran \\ ${ }^{2}$ Assistant Professor, Infectious Disease and Tropical Medicine Research Center, Zahedan University of Medical Sciences, Zahedan, IR Iran \\ ${ }^{3}$ Associate Professor, Children and Adolescent Health Research Center, Oral and Dental Disease Research Center, Dept of Pediatric Dentistry, School of Dentistry, Zahedan \\ University of Medical Sciences, Zahedan, IR Iran \\ ${ }^{4}$ Dentist, Zahedan University of Medical Sciences, Zahedan, IR Iran \\ "Corresponding author: Nahid Ramazani, Department of Pediatric Dentistry, School of Dentistry, Azadegan st, Khorramshahr Ave, Zahedan, IR Iran. Tel: +98-5433423218; \\ +98-9155009085, Fax: +98-5433414005, E-mail: ramazani_nahid@yahoo.com
}

Received 2016 February 02; Revised 2016 February 18; Accepted 2016 February 21.

\begin{abstract}
Background: Periodontal infections are factors associated with systemic diseases such as diabetes mellitus, chronic obstructive pulmonary disease (COPD), cardiovascular diseases, preterm birth, low birth weight, and cerebral vascular diseases.

Objectives: This study aimed at comparing the periodontal status between patients with COPD and healthy subjects.

Methods: This case-control study was done on 20 COPD patients (including 9 females and 11 males) and 20 non-COPD healthy subjects (including 11 females and 9 males) within the age range of 30 to 65 years old. In the COPD group, the subjects were all nonsmokers and without any systemic illness, apart from COPD. The mean clinical attachment loss (CAL), probing pocket depth (PPD), and sulcus bleeding index (SBI) was calculated and compared between the two groups. For data analysis, Mann-Whitney U and chisquare were employed using the SPSS 18 software.

Results: The amount of CAL in COPD and healthy groups was $4.57 \pm 1.4$ and $2.38 \pm 0.8$, respectively $(\mathrm{P}<0.001)$. The amount of PPD in COPD and healthy groups was $2.32 \pm 0.69$ and $2.12 \pm 0.41$, respectively $(\mathrm{P}=0.28)$. The amount of SBI in COPD and healthy groups was $100 \%$ and $75 \%$, respectively $(\mathrm{P}=0.017)$.

Conclusions: Although the investigated sample size did not suffice for deducing an exact conclusion, results indicated a probable association between periodontal disease and COPD.
\end{abstract}

Keywords: Chronic Obstructive Pulmonary Disease, Periodontal Disease, Periodontal Parameters

\section{Background}

Recent studies have reported on the effect of oral infections, especially periodontal diseases, on the period and pathogenesis of systemic diseases. Risk factors of periodontal diseases include local factors, environmentalbehavioral factors, systemic factors, genetic factors, etc. (1). Systemic diseases such as osteoporosis, diabetes, and immune disorders may increase the risk of periodontal problems (2); however, less attention has been paid to the role of oral diseases in systemic health.

Oral diseases, including periodontal infections, are a risk factor for systemic diseases such as diabetes mellitus, respiratory tract diseases such as pneumonia and chronic obstructive pulmonary disease (COPD), cardiovascular diseases, preterm birth, low birth weight, and cerebral vascular diseases (3). Periodontal diseases are common oral infectious problems that affect the periodontium and lead to the loss of alveolar bone, ligaments support, and ultimately the teeth $(4,5)$.
Periodontal diseases are more prevalent among older, tobacco-smoking males (6). Chronic obstructive pulmonary disease is diagnosed by having airflow obstruction caused by chronic bronchitis or emphysema. In this disease, mucous glands are enlarged and an inflammatory process occurs in neutrophils and complex inflammatory cells in pulmonary tissue. Tobacco smoking is the main risk factor of COPD (7). It is a chronic infectious pulmonary disease that is associated with reduced lung function and is common among older cigarette-smoking males $(8,9)$. This disease, as a major cause of mortality around the world, has afflicted about 200 million people globally (10).

Several mechanisms, including aspiration of oral bacteria into the respiratory tract, and/or transfer of gingival sulcus and periodontal pocket bacteria to the lung, through infiltration to the blood cycle, have caused COPD to be influenced by periodontal disease $(11,12)$. Periodontal disease changes biological conditions of bacteria and leads to the formation of colonies in the mucous and the devel- 
opment of infection with respiratory pathogens (13).

Moreover, periodontal bacteria release the following cytokines, Interleukin (IL) $1 \beta$, IL1 $\alpha$, tumor necrotizing factor (TNF)- $\alpha$, IL8, and IL6, which infiltrate into the respiratory tract. Additionally, cytokines released from respiratory epithelium due to the attachment of oral pathogens cause neutrophils infiltration in the parenchyma of airways and release hydrolytic and proteolytic enzymes, as well as free oxygen radicals. This finally results in damage to the respiratory epithelium and exposes sub-epithelial receptors to respiratory pathogens. These pathogens are colonized after attachment to those receptors, and thus make the individual prone to respiratory infections $(14,15)$.

Chronic obstructive pulmonary disease and periodontal disease have a similar pathogenic mechanism. In both, the inflammatory response of host to the pathogenic factor (smoking in COPD and bacteria in periodontal) increases. As a result, neutrophils are released and directly cause tissue damage via the secretion of oxidative and hydrolytic enzymes. The activation of monocytes and macrophages also leads to more secretion of preinflammatory mediators (1). In COPD patients, the frequency and intensity of periodontal diseases indicate an association between COPD and periodontal disease; therefore, prophylaxis and treatment of periodontal diseases should be considered in the treatment of COPD (16).

\section{Objectives}

Regarding the contradictory results of previous studies, this study aimed at investigating and comparing the periodontal condition of COPD patients with non-COPD individuals.

\section{Methods}

Out of 40 subjects examined in this study, 20 were allocated to each of the COPD (case) and non-COPD (control) groups. Inclusion criteria were as follow, no systemic disease other than COPD, no periodontal treatment in the past 1 year, no smoking, and no drug usage other than ones prescribed for COPD treatment. The subjects were selected from those visiting the lung ward of Emam Ali hospital, after they were examined and diagnosed with COPD by the internal specialist. They were then referred to the periodontics department of the Faculty of Dentistry of Zahedan for periodontal examination, after their written informed consent was obtained. The subjects in the control group were selected from individuals accompanying the patients at the hospital, after their informed consent was obtained. The examination and completion of the periodontal chart was done by an intern and under the supervision of a supervisor at the periodontics department. Using a periodontal probe (Williams), the amount of PPD (mm) was measured from gingival margin to pocket depth. Then, the amount of clinical attachment loss (CAL) in all subjects was calculated with a periodontal probe through measuring the distance from the Cemento Enamel junction (CEJ) to the pocket depth and gingival margin.

Moreover, the sulcus bleeding index (SBI) was determined for all participants after probing the base of the pocket from mesial to distal of the adjacent tooth as follows: Code " 0 " indicated a lack of bleeding, code "1" referred to bleeding that occurred during probing or within 15 seconds after it (17). Finally, free dental scaling was provided to the eligible subjects. In case of a need for dental surgery, required guidance was provided. Data were analyzed by the Mann-Whitney U and chi-square test using the SPSS 18 software.

\section{Results}

This study aimed at comparing periodontal status in patients with Chronic obstructive pulmonary disease (COPD) and healthy individuals. The study was conducted on 20 patients with COPD and 20 patients without COPD. Of the patients without COPD, $45 \%$ were male and 55\% were female. Of the COPD patients, $55 \%$ were male and $45 \%$ were female (Table 1$)$.

Table 1. Frequency of Male and Female Subjects ${ }^{\mathrm{a}, \mathrm{b}}$

\begin{tabular}{lcc}
\hline \multirow{2}{*}{ Group } & \multicolumn{2}{c}{ Gender } \\
\cline { 2 - 3 } & Male & Female \\
\hline Without COPD & $9(45)$ & $11(55)$ \\
With COPD & $11(55)$ & $9(45)$ \\
\hline
\end{tabular}

${ }^{\mathrm{a}}$ Values are expressed as No. (\%).

${ }^{\mathrm{b}}$ Chi-square test, $\mathrm{x}^{2}=0.4, \mathrm{df}=1, \mathrm{P}=0.53$.

The results showed that clinical attachment loss (CAL) variable was different between healthy individuals and patients with COPD in both age groups (group 1: individuals $\leq 45$ years of age and group 2: individuals $>45$ years of age) (Tables 2 and 3 ).

According to Table 4, the measurement results shown that the average CAL in COPD patients was higher than healthy individuals.

According to Table 4, the measurement results showed that the average probing pocket depth (PPD) in patients with COPD was higher than healthy individuals; however, this was not statistically significant. 
Table 2. Clinical Attachment Loss and Probing Pocket Depth in Individuals $\leq 45$ Years of Age

\begin{tabular}{lccc}
\hline Group & CAL & PPD & Number \\
\hline Without COPD & $2.22 \pm 0.77$ & $2.14 \pm 0.36$ & 15 \\
With COPD & $3.21 \pm 0.85$ & $2.51 \pm 0.48$ & 3 \\
PValue & 0.06 & 0.15 & \\
\hline
\end{tabular}

Table 3. Clinical Attachment Loss and Probing Pocket Depth in Individuals $>45$ Years of Age $\mathrm{a}^{\mathrm{a}}$

\begin{tabular}{lccc}
\hline Group & CAL & PPD & Number \\
\hline without COPD & $2.86 \pm 0.8$ & $2.06 \pm 0.55$ & 5 \\
with COPD & $4.81 \pm 1.36$ & $2.28 \pm 0.72$ & 17 \\
P Value & 0.001 & 0.53 & \\
\hline
\end{tabular}

${ }^{\mathrm{a}}$ Test: Mann-Whitney U.

The results of the comparison of CAL, PPD, and SBI variables between the healthy group and patients with COPD showed that CAL in patients with COPD was significantly higher than in healthy individuals. Probing Pocket Depth in COPD patients was higher than in healthy individuals. The SBI in patients with COPD patients was significantly higher than healthy individuals.

\section{Discussion}

The hypothesis for the correlation between periodontal disease and COPD stems from their similar pathophysiological mechanisms. In both diseases, host inflammatory response increases in response to pathogens. As a result, neutrophils are released and cause tissue damage by secretion of oxidative and hydrolytic enzymes. Periodontal diseases change the environmental conditions for bacterial growth, leading to the colonization of mucosal surfaces and infection by respiratory pathogens (13). This study aimed at comparing COPD patients with healthy individuals in terms of their periodontal status. Accordingly, the average CAL, PPD, and SBI in both groups (COPD patients and healthy individuals) were examined and compared.

In this study, the average CAL in COPD patients and healthy individuals groups was $4.57 \pm 1.4$ and $2.38 \pm 0.8$, respectively. The average PPD in COPD patients and healthy individuals was $2.32 \pm 0.69$ and $2.12 \pm 0.41$, respectively. Moreover, $75 \%$ and $100 \%$ of the healthy individuals and patients with COPD had bleeding, respectively. Clinical attachment loss in the 2 age groups (group 1: individuals $\leq 45$ years of age and group 2: individuals $>45$ years of age) was different between healthy individuals and patients with COPD.
Deo et al. conducted a study on 150 patients with COPD and 50 individuals without COPD. They measured and compared CAL, PPD, OHI, and blood loss. In the COPD patients and healthy individuals, CAL was 4.22 and 3.92, respectively. Moreover, in the COPD patients group and healthy individuals, $\mathrm{OHI}$ was 3.37 and 2.87, respectively. The percentage of individuals with blood loss of less than $20 \%$ was lower in COPD patients than in those without COPD ( $4 \%$ for COPD patients and $12 \%$ for those without COPD)(18). These results were consistent with the results of the present study.

Leuckfeld et al. conducted a study on 130 patients with COPD and 80 individuals without COPD. They concluded that the mean marginal bone level from the CEJ was 8.4 $\mathrm{mm}$ and $2.7 \mathrm{~mm}$ in patients with COPD and those without COPD, respectively. The mean marginal bone level in this study was consistent with that of CAL (3). Prasanna conducted a study and measured the periodontal indices of papilla bleeding index (PBI), plaque index (PI), and periodontal index for Risk of Infectiousness (PIRI). Moreover, they found that patients with COPD had higher periodontal indices than those without COPD. These results are consistent with the results of the present study (19) $(G I=2.01$, $\mathrm{PI}=4.96, \mathrm{PBI}=2.89$, and $\mathrm{PIRI}=5.8$ ).

Si et al. conducted a study and concluded that the indices of CAL, BI, and PI in patients with COPD are higher than healthy individuals, which is similar to the results of the present study (20). Moreover, a study by Sayar et al. showed that $9.2 \%$ and $29.2 \%$ of the members of control and case groups had a PD greater than $3 \mathrm{~mm}(\mathrm{P}<0.05)$, respectively. Patients with COPD were 3.4 times more exposed to a PD greater than $3 \mathrm{~mm}$ than the control group. In the control and case groups, $49.5 \pm 11.7$ and $63.5 \pm 15.2(\mathrm{P}<0.0001)$ of the teeth had bleeding on probing, respectively, and patients with COPD were 1.8 times more exposed to GB than the control group. In the control and case groups, 61.5\% and $80 \%$ had a Periodontal Attachment Loss (PAL) greater than $2 \mathrm{~mm}$, respectively $(\mathrm{P}<0.02)$, and patients with COPD were 2.5 times more exposed to a PAL of $\geq 2$ when compared to the control group. Average and high PI in the control and case groups were $24.6 \%$ and $44.6 \%(\mathrm{P}<0.02)$, and patients with COPD were 47.2 times more exposed to average and high PI when compared with the control group (17). These results are consistent with the results of the present study.

Moreover, these results are inconsistent with the results of the study by Scannapieco and Ho, in which no difference was found between patients with COPD and healthy individuals in terms of periodontal indices of PI, gingival index (GI), and PPD (7). This could be due to the limitation of the above-mentioned study in terms of numbers.

Considering the results in terms of significant differ- 
Table 4. Comparison of Clinical Attachment Loss, Probing Pocket Depth and Sulcus Bleeding Index between Patients With Chronic Obstructive Pulmonary Disease and Healthy Individuals ${ }^{\mathrm{a}, \mathrm{b}}$

\begin{tabular}{|c|c|c|c|c|}
\hline \multirow[t]{2}{*}{ Group } & \multirow[t]{2}{*}{ CAL } & \multirow[t]{2}{*}{ PPD } & \multicolumn{2}{|c|}{ SBI } \\
\hline & & & Code 0 & Code 1 \\
\hline Without COPD & $2.38 \pm 0.80$ & $2.12 \pm 0.41$ & $5(25.0)$ & $15(75.0)$ \\
\hline With COPD & $4.57 \pm 1.4$ & $2.32 \pm 0.69$ & $0(0.0)$ & $20(100.0)$ \\
\hline PValue & $<0.001^{\mathrm{c}}$ & $0.28^{\mathrm{c}}$ & $0.017^{\mathrm{d}}$ & \\
\hline
\end{tabular}

${ }^{\mathrm{a}}$ Values are expressed as No. (\%).

${ }^{\mathrm{b}}$ Code 0 : No bleeding is observed; Code 1: bleeding occurs on probing or within 15 seconds after probing.

${ }^{\mathrm{c}}$ Mann-Whitney U.

${ }^{\mathrm{d}}$ Chi-square.

ences in CAL and SBI between the two groups, it may be concluded that there is an association between periodontal diseases and COPD, and treatment of periodontal diseases can influence the prognosis and treatment process of COPD. In addition, when treating COPD, the causes of the disease should be identified and treated. In other words, symptomatic treatment is not adequate. It is recommended for the periodontal status of COPD patients to be examined initially, followed by investigation of the effect of periodontal treatment on the prevention of COPD (even for other diseases such as myocardial infarction [MI], low birth weight, preterm labor, and pneumonia).

\section{Acknowledgments}

This article was derived from a general dentistry dissertation approved by the deputy of Research and Technology of Zahedan University of Medical Sciences. The authors thank the deputy for financial supports.

\section{Footnote}

Authors' Contribution: Mohammad Ayoub Rigi-Ladiz, Nezar Ali Moulaei, and Nahid Ramazani designed the research protocol. Sample preparation and data acquisition was performed by Mohaddese Khajemahmood. All authors read and approved the final manuscript.

\section{References}

1. Newman MG, Takei H, Klokkevold PR, Carranza FA. Carranza's clinical periodontology. Elsevier health sciences; 2011.

2. Garcia RI, Henshaw MM, Krall EA. Relationship between periodontal disease and systemic health. Periodontol 2000. 2001;25:21-36. [PubMed: 11155180].

3. Leuckfeld I, Obregon-Whittle MV, Lund MB, Geiran O, Bjortuft O, Olsen I. Severe chronic obstructive pulmonary disease: association with marginal bone loss in periodontitis. Respir Med. 2008;102(4):488-94. doi:10.1016/j.rmed.2007.12.001. [PubMed:18191392].
4. Morris AJ, Steele J, White DA. The oral cleanliness and periodontal health of UK adults in 1998. Br Dent J. 2001;191(4):186-92. doi: 10.1038/sj.bdj.4801135a. [PubMed: 11551090].

5. Laine ML, Crielaard W, Loos BG. Genetic susceptibility to periodontitis. Periodontol 2000. 2012;58(1):37-68. doi: 10.1111/j.16000757.2011.00415.x. [PubMed: 22133366].

6. Pihlstrom BL. Periodontal risk assessment, diagnosis and treatment planning. Periodontol 2000. 2001;25:37-58. [PubMed: 11155181].

7. Scannapieco FA, Ho AW. Potential associations between chronic respiratory disease and periodontal disease: analysis of National Health and Nutrition Examination Survey III. J Periodontol. 2001;72(1):50-6. doi: 10.1902/jop.2001.72.1.50. [PubMed: 11210073].

8. Mannino DM, Davis KJ. Lung function decline and outcomes in an elderly population. Thorax. 2006;61(6):472-7. doi: 10.1136/thx.2005.052449. [PubMed: 16517577].

9. Buist AS, McBurnie MA, Vollmer WM, Gillespie S, Burney P, Mannino DM, et al. International variation in the prevalence of COPD (the BOLD Study): a population-based prevalence study. Lancet. 2007;370(9589):741-50. doi: 10.1016/S0140-6736(07)61377-4. [PubMed: 17765523].

10. Lopez AD, Mathers CD, Ezzati M, Jamison DT, Murray CJ. Global and regional burden of disease and risk factors, 2001: systematic analysis of population health data. Lancet. 2006;367(9524):1747-57. doi: 10.1016/S0140-6736(06)68770-9. [PubMed:16731270].

11. Finegold SM. Aspiration pneumonia. Rev Infect Dis. 1991;13 Suppl 9:S737-42. [PubMed: 1925318].

12. Morris JF, Sewell DL. Necrotizing pneumonia caused by mixed infection with Actinobacillus actinomycetemcomitans and Actinomyces israelii: case report and review. Clin Infect Dis. 1994;18(3):450-2. [PubMed: 8011834]

13. Hayes C, Sparrow D, Cohen M, Vokonas PS, Garcia RI. The association between alveolar bone loss and pulmonary function: the VA Dental Longitudinal Study. Ann Periodontol. 1998;3(1):257-61. doi: 10.1902/annals.1998.3.1.257. [PubMed: 9722709].

14. Wilson M, Reddi K, Henderson B. Cytokine-inducing components of periodontopathogenic bacteria. J Periodontal Res. 1996;31(6):393-407. [PubMed: 8884633].

15. Birkedal-Hansen $\mathrm{H}$. Role of cytokines and inflammatory mediators in tissue destruction. J Periodontal Res. 1993;28(6 Pt 2):500-10. [PubMed: 8263720].

16. Kowalski M, Kowalska E, Split M, Split W, Wierzbicka-Ferszt A, Pawlicki L, et al. [Assessment of periodontal state in patients with chronic obstructive pulmonary disease-part II]. Pol Merkur Lekarski. 2005;19(112):537-41. [PubMed: 16379320].

17. Sayar F, Habibi M, Velaei N. Relationship between periodontal and chronic obstructive pulmonary diseases. Beheshti Univ Dent J. 2004;22(2):239-46. 
18. Deo V, Bhongade ML, Ansari S, Chavan RS. Periodontitis as a potential risk factor for chronic obstructive pulmonary disease: a retrospective study. Indian J Dent Res. 2009;20(4):466-70. doi: 10.4103/09709290.59456. [PubMed: 20139573].

19. Prasanna SJ. Causal relationship between periodontitis and chronic obstructive pulmonary disease. J Indian Soc Periodontol.
2011;15(4):359-65. doi: 10.4103/0972-124X.92570. [PubMed: 22368360]. 20. Si Y, Fan H, Song Y, Zhou X, Zhang J, Wang Z. Association between periodontitis and chronic obstructive pulmonary disease in a Chinese population. J Periodontol. 2012;83(10):1288-96. doi: 10.1902/jop.2012.110472. [PubMed: 22248220]. 